\title{
Bodily Changes And Coping Strategies Due To Adjuvant Anti- Hormonal Breast Cancer Therapy-A Focus Group Study
}

\author{
Anna-Carin Uttermalm, MSc, RPT ${ }^{\mathrm{a}}$, Anna von Wachenfeldt, MD, PHD \\ Elisabet Lidbrink, MD, PHD ${ }^{c}$, Aina Johnsson, MSW, PHD \\ ${ }^{a}$ Hela Kroppen Physiotherapy, Stockholm, Sweden

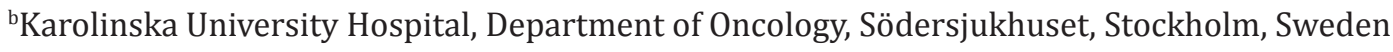 \\ 'Karolinska Institutet Department of Oncology and Pathology, Stockholm, Sweden \\ ${ }^{d}$ Karolinska University Hospital, Department of Social Work, Stockholm, Sweden \\ aina.johnsson@karolinska.se
}

\begin{abstract}
Breast cancer is the most common female cancer worldwide. In the majority of cases, the breast tumour is hormone receptor-positive and the woman is prescribed 5 years of adjuvant anti-hormonal therapy. Many women experience side effects from the treatment. Symptoms can be so severe that some women choose to discontinue treatment. This study was conducted in order to find methods to support women treated with adjuvant anti-hormonal breast cancer therapy to complete their treatment, by elucidating how they experience the side effects and how they act and reflect on coping and on rehabilitation- related issues.

The study includes twelve women from two focus group interviews. The recorded interviews were analysed using qualitative content analysis with an inductive approach. The women felt alienated from their body, which they felt had aged a lot. They reported symptoms from the joints and muscles, such as pain, aching and stiffness, and muscle cramps. They also reported fatigue and menopausal symptoms. The bodily changes were strong hindrances when they tried to live and work as before. They felt that they had been given insufficient information about the anti-hormonal therapy and its side effects. They also felt they lacked support from the health care providers in how to cope with the symptoms. They furthermore had a sense of a large obstacle in the way of getting started with any physical activity. Overall, the women had an impaired self-reliance on the body. The fact that women, when offered rehabilitation, experienced it positively and managed it well can motivate those providing medical care to develop rehabilitation programmes adapted to the individual's needs. Better rehabilitation programmes and improved information about the therapy and its side effects may make it easier for women with breast cancer to complete the anti-hormonal therapy.
\end{abstract}

Key words: Breast Cancer; Anti-Hormonal Treatment; Side Effects, Rehabilitation; Coping Strategies, Adherence

\section{INTRODUCTION}

Breast cancer is the most common female cancer worldwide, and there has been an increase in incidence over the last decades (Stewart \& Wild, 2014). The majority, up to 80 percent, of breast tumours are hormonereceptor positive, which means dependent on female sex hormones, to grow (Li, Daling, \& Malone, 2003). In order to prevent recurrence, women with hormone-sensitive tumours are prescribed five or more years of antioestrogen treatment. Five years of treatment with tamoxifen reduces the recurrence rate by 39 percent over the first 10 years (Davies et al., 2011). Including an aromatase inhibitor (AI) at some point in the anti-hormonal 
adjuvant treatment reduces the risk of recurrence compared to tamoxifen as the only anti-hormonal treatment (Burstein et al., 2010). The anti-hormonal treatment, however, is associated with side-effects.

The most common side-effect reported during treatment with tamoxifen is menopausal symptoms, such as vasomotor symptoms, fatigue, and nausea (Buijs, de Vries, Mourits, \& Willemse, 2008; Fenlon \& Rogers, 2007; Fenlon, Corner \& Haviland, 2009). Side-effects are sometimes severe enough to affect life satisfaction (Skördåker et al, 2015) and work ability (Johnsson et al., 2007). Studies show that vasomotor symptoms are reported to be the symptoms experienced as the most difficult to manage (Loibl, Lintermans, Dieudonne, \& Neven, 2011).

Women with breast cancer have more joint and muscle aches, pain and stiffness compared with women without breast cancer (Fenlon et al, 2013). During treatment with AI, joint pain is reported to be a side-effect difficult to manage (Burstein, 2007). The problem was normalized when treatment was completed, but can cause great difficulty during therapy in performing activities of daily living (Burstein, 2007; Coleman et al., 2008; Gaillard \& Stearns, 2011; Henry, Giles, \& Stearns, 2008). A patient with a history of mild or moderate joint problems often gets worse problems when treated with AI. However, even patients with no earlier joint problems can develop problems and up to 46 percent of women treated with AI suffer from osteoarthritis, tendonitis, carpal tunnel syndrome, or bursitis (Din, Dodwell, Wakefield, \& Coleman, 2010). 50 percent of women who started the AI treatment had new or worsening musculoskeletal pain, and the problems usually started within eight weeks after starting treatment (Singer et al., 2012). An additional side effect of this treatment is bone demineralization with an increased risk of osteoporosis and fractures (Gaillard \& Stearns, 2011).

Achieving a successful breast cancer treatment requires adherence to the prescribed treatment, but unfortunately adherence to anti-hormonal therapy is declining rapidly over time (Ziller et al., 2009). A retrospective study of Swedish women with breast cancer showed that about 30 percent had discontinued anti-hormonal therapy at a three-year follow-up from baseline, and 50 percent of these had discontinued treatment in the first year (Wigertz et al., 2012).

This study was conducted in order to find methods to support women treated with adjuvant anti-hormonal breast cancer therapy to complete their treatment, by elucidating how they experience the side effects and how they act and reflect on coping and on rehabilitation- related issues.

\section{SUBJECTS AND METHODS}

The study is based on two focus group interviews with 12 recruited women. A qualitative content analysis with an inductive approach was used to analyse the interviews.

\section{Sampling}

The sampling frame comprised women who lived in Stockholm and had started adjuvant anti-hormonal breast cancer therapy within the past five years. Two groups were organized with five and seven women, respectively. The first group was selected by the first five women who enrolled for the study. All women in this group were older than 50 years. In order to increase the potential to gather as nuanced information as possible, younger women were selected to participate in focus group number two.

A total of twelve women participated in the study. They were between 36 and 71 years old. Ten women had a college education and one had a secondary education. Information on education is missing for one woman. Ten women were working and two were retired. Seven women received tamoxifen as adjuvant anti-hormonal therapy and five were treated with AI. Nine of the twelve women had undergone chemotherapy. 


\section{Procedure}

Recruitment of participants was done in waiting areas at oncological clinics in two hospitals in Stockholm. A breast cancer association in Stockholm also helped with recruitment via email to all their members. The notices and the email described the study and its purpose. Interested women were invited to contact the research director and then received additional oral and written information about the study, its voluntary nature, and confidentiality.

\section{Data Collection}

We performed a purposeful sampling from women described by Kamberelis and Dimitriadis (2005). The two interviews were conducted in a hospital in Stockholm in 2013. Interviews lasted for 90 minutes with a 15 -minute break after 60 minutes. The interviews were based on an interview guide developed by the first author and discussed in depth with the co-authors to address the following issues:

1. How did the women experience the adjuvant anti-hormonal therapy?

2. To what extent did they have the following symptoms: joint/muscle/pain problems and menopausal symptoms?

3. What other experiences did they associate with the therapy?

4. Did they have any strategies to cope with the side effects?

5. Did they participate in any form of rehabilitation and, if so, did the rehabilitation programme reduce their problems?

6. Did they have contact with/receive treatment from a physiotherapist? If so, what was the reason for this? What benefit did they feel they got from this treatment?

7. Did they feel they had the strength to carry out the therapy?

Focus group interviews were carried out as described by Chrzanowska (2002) and Krueger (1994).

The interviews were tape-recorded and transcribed verbatim.

\section{Data analysis}

The recorded interviews were analysed using qualitative content analysis with an inductive approach as described by Lundman \& Graneheim (2010) and by Patton (2002). The recordings were transcribed and analysed by the first author. The interviews were read several times to get an idea of the content as a whole. Words and sentences that were connected through their content and context were combined into meaningful units. After this, the meaningful units were condensed. The condensed text was provided with codes. The codes were then combined into subcategories and categories. Finally, themes were formulated to indicate the underlying meaning in interviews. After the analysis was made the moderator/last author and the first author reviewed both transcription and text analysis together. The other co-authors have read the transcription and checked the text analysis.

\section{Ethics}

The study was approved by the Regional Ethical Review Board in Stockholm in 2013.

\section{RESULTS}

The content analysis of the focus groups yielded three themes with several categories and sub-categories in each theme. The themes were: Side effects/The changing body; Coping strategies; and Experiences 
regarding rehabilitation. Study participants have been given fictitious names. Names beginning with the letter A represent participants in interview group 1 and those beginning with a B participated in interview group 2.

\section{Theme 1: Side effects/The changing body}

\section{Symptoms from the joints and muscles}

The women's experiences due to the anti-hormonal therapy were symptoms such as pain, aching, stiffness and cramps from the joints and muscles. The symptoms decreased slightly over time, but this did not eliminate the fact that the women felt uncomfortable. The women felt that they had had insufficient information from the health care providers about the anti-hormonal therapy and how to handle the side effects.

\section{Menopause symptoms}

The women experienced poorer quality of life due to menopausal symptoms such as sweating and hot flushes. They complained of constantly having to adjust their clothing, taking off their clothes, needing to open a window, or always feeling uncomfortable.

\section{Physical and mental fatigue}

The women described the experience of both physical and mental fatigue. They felt a lack of energy and had lost strength after the anti-hormonal therapy was started. Physical and mental strength could vary from one day to the next; they reported how their energy might suddenly run out during an activity. So it was difficult to judge how much they would be able to do.

\section{The alienated body}

The women felt alienated from their body, which they felt had aged a lot. The effects of feeling an alienated body, due to the symptoms, gave the women a reduced trust in their body, resulting in an impaired selfreliance based on the feeling that they could not feel, and did not know, their body's limitations. They felt they could not dare to use their bodies like before. The women's activity levels were reduced in terms of both leisure time and work. They could no longer manage as many physical activities as they wished. This became a threshold for starting up physical activities. The women reported that they did not like their 'new' body and missed the old one. This became a strong hindrance when they tried to live and work as before.

The women reported a conflict between not wanting to take the medication because of all the side effects, and understanding that it was an important part of the treatment. Knowing that the medication had to be continued for 5 years contributed to increasing concerns about how they would manage with the side effects.

The doctors say that it's important; I still think that 5 years is a long time, feels like an eternity. Half a year of chemotherapy, an operation, and radiotherapy - that you could see the end of. (Astrid)

\section{Theme 2: Coping strategies}

\section{Problem-focused coping}

The women had various coping strategies. They tried to minimize the side effects in many different ways, for example by changing the time of the day when they took the anti-hormonal medicine, halving the dose to reduce symptoms or taking drugs for various side effects. Some women took antidepressants. This gave some relief, but then they might feel worse from the side effects of the antidepressants. One woman said 
she did not want to expose her body to more 'manipulation' than it had already suffered. In order to get rid of the side effects some women had discussed discontinuing the anti-hormonal therapy with a doctor.

Another strategy was to exercise. Most women believed that physical activity was a facilitating factor in managing at least some of the symptoms. It was comforting to know that they could do something to ease the symptoms and have some control over them, but they also felt that they had lost the power to act. The alienated body, with new symptoms, became a threshold that had to be overcome before starting up activities. Compared with how things were before cancer treatment, their body felt old and unreliable.

Exercising helped them maintain their weight, reduce stress, sleep better and feel better overall. It was easier to find peace of mind and bodily wellness through exercise. Many of the women also thought that symptoms from the joints and muscles decreased with physical activity. Physical activity did not diminish sweating/flushing, but it felt more natural to sweat when this was expected.

\section{Emotion-focused coping}

Several women used emotion-focused strategies to stop thinking about the side effects and focus more on the fact that the medicine reduces the risk of relapse. They were better at listening to the body and accepted that the changing body had less energy than before.

I think I have to listen to myself, and think, OK now I feel like this. Stop and do something else, because you haven't got the energy; sort of accept and try and take that as a strategy. (Agnes)

They discussed the medicine and compared it to an embankment that would keep the disease away now that the other treatments were completed. They also expressed the idea that the medicine did them good, which made it easier to accept the side effects.

I turned it around when I got the first side effects. Well, good; then it works. That has to be positive. (Bia)

\section{Theme 3: Experiences regarding rehabilitation}

\section{Lack of support regarding rehabilitation from the health care providers}

The women stated that they had poor support and lack of information about opportunities for rehabilitation, from the health care providers. They felt that the health care providers did not pay attention to their symptoms and their desire for relief from side effects. This gave them a sense of isolation, insecurity and lack of support in how to proceed with rehabilitation. Some felt that they were considered to be 'too healthy' for rehabilitation.

The women stated that it took responsibility and personal initiative to get help with the problems. Because of the threshold to start up activities of their own, the women wished they had received more support and more coherent information about opportunities to get help with rehabilitation in the final stages of treatment in the hospital.

A visit to the physiotherapist to make a plan for what I should do, how I can manage in a positive way ... (Birgitta)

\section{Experiences of rehabilitation}

Rehabilitation activities were often carried out by an outpatient physiotherapist and were focused on physical exercise. Another form of rehabilitation was 12 days in a cancer rehabilitation clinic, where participants were given psychosocial support, education and information about breast cancer, as well as physical exercise.

The women who had participated in a rehabilitation programme were positive. Those who had participated in rehabilitation programmes in an in-patient setting or in various forms of physical activity in groups or 
individually in an out-patient setting felt that they had managed the programme well and sometimes even better than expected.

The rehabilitation helped the women to dare to try to use their body again. They learned to find limits to what their body could tolerate. This improved their self-reliance in terms of their body.

It was good. I felt a lot that, Wow, I can do this thing. Mostly because I was so scared of that part [i.e. having lost the ability to do activities]. (Agnes)

The rehabilitation period was also seen as an end to the convalescence and a springboard from which to move on.

\section{I thought that I managed it quite well. A kick-off to get going. (Beda)}

\section{DISCUSSION}

The results of this study showed that women with a breast cancer diagnosis who received anti-hormonal therapy experienced a variety of physical and psychological symptoms. Thus the women were prescribed the therapy for five years; this meant significant changes in their lives. The problems affected the women both in daily life activities and occupationally. The women felt that they received insufficient information from the health-care providers about the anti-hormonal therapy, medical advice how to reduce the sideeffects and information regarding rehabilitation. They developed their own strategies to manage their symptoms and sometimes also received help with rehabilitation from physiotherapists in primary care or in rehabilitation clinics.

The women in this study felt that their bodies had changed due to the side-effects of the endocrine therapy. This result is in agreement with previous reports. Shapiro and colleagues describe that breast cancer, through treatments, leads to concerns about the woman's way of looking at herself. The impact of breast cancer treatments becomes a threat to a woman's self-image (Shapiro et al., 2001).

The women described an impaired self-efficacy. Self-efficacy according to Bandura is an individual's confidence in the ability to perform behaviour, based on past ability to control the behaviour (Bandura, 1986). The women had an impaired confidence in their body because they felt that they could not manage as much physical activity as before; they felt weaker and more fragile due to the side effects such as joint and muscle pain, menopausal symptoms, and fatigue. The menopause symptoms were difficult to handle for the women. This result is in agreement with previous reports. According to Loibl and colleagues, the nightly sweats are something that women find difficult to manage (Loibl, et al., 2011). The women in this study described that sweating is not reduced by physical activity but it felt more natural to sweat when this was expected and that the training itself gave an inner peace and better night's sleep. The positive effects of increased mental well-being of physical activity may have a role to play by increasing the conditions to manage the stress better, that sweating / flushing may cause. The women in the study also experienced weight gain after the anti-hormonal treatment started. They felt, however, that regular physical activity helped them to maintain weight.

The women experienced increased physical and mental fatigue after they started the anti-hormonal therapy. They could not achieve the same activity level as before the treatment because of these symptoms. A study by Huang and colleagues stated that fatigue is a major problem in most of the breast cancer patients during the anti-hormonal therapy. Sixty percent of the studied women stated that they were fatigued. Among the non-pharmacological methods, physical activity had the most significant positive impact in reducing fatigue symptoms. However, the article points out the difficulty of separating fatigue caused by the anti-hormonal therapy and other cancer treatments (Huang, Zhang, Kang, Song, \& Zhao, 2010). Egan 
and colleagues stated in a review that there is good evidence that exercise and rehabilitation focused on physical activity can reduce fatigue due to breast cancer treatment. They also showed that there is preliminary evidence that physical activity can reduce pain, improve sexual function, and improve the cognitive function of women treated with anti-hormonal therapy (Egan et al., 2013).

The women in this study felt that they had received insufficient information from the health care providers about the anti-hormonal therapy and its side effects. That this is a problem has recently been highlighted in several other studies (Stjarnfeldt et al, 2015).The women were ambivalent about taking the medicine because of side-effects. Another conflict where having to medicate for such a long time was their worry as to whether they could manage the offered treatment 'all the way'. However, the women found several strategies to cope with their new situation. Their strategies correspond with coping theories of Lazarus and Folkman (1984). The women in this study had used both problem-focused and emotion-focused coping. Problem-focused coping could include finding ways to reduce side-effects, such as experimenting with which time of the day was the best to take the medication. The majority of women also had, on their own way, found various physical activities that reduced the symptoms. Emotional coping could include thinking positively, for example, that symptoms actually showed that the drug is effective and that it leads to a healthy life. It could also include accepting discomfort and reducing the demands of daily life.

Although the women in this study believed that physical activity is salutary, they also had a sense of a large obstacle in the way of getting started with physical activity, that there was a start-up threshold to overcome. It is important for women with a breast cancer diagnosis who receive anti-hormonal therapy to be physically active for many reasons. Singer and colleagues believe that it is important to be physically fit prior to starting treatment with the AI drugs to reduce the risk of subsequent AI-induced arthritis. Women's physicians should be aware of the risks associated with impaired physical function in order to recommend the appropriate regimen to the patient before starting treatment (Singer, et al., 2012). Coleman and colleagues suggest that milder forms of musculoskeletal disorders should lead to information about lifestyle changes, physical exercise, and weight loss (Coleman, et al., 2008).

The studied women who had participated in a rehabilitation programme were positive. They managed the rehabilitation programme well and even better than they thought. They also learned to adapt the physical activity to their own capacities. Rehabilitation increased their faith on their own resources regarding the body's capacity and the various forms of physical activity that suited them. This corresponds with SCT and the theory of self-efficacy, which the literature describes as having significant impact on increasing these women's physical activity (Phillips \& McAuley, 2013; Rogers et al., 2005).

\section{CONCLUSION}

The women in this study felt alienated from their body. They felt their body had aged drastically during treatment. The bodily changes were strong hindrances when they tried to live and work as before. The women had a sense of there being a large obstacle in the way of getting started with any physical activity. They also had an impaired self-reliance on the body. The women used various coping strategies. They tried to minimize the side effects in many different ways. They used strategies to stop thinking about the side effects and focus more on the fact that the medicine reduces the risk of relapse. The women felt that they had had insufficient information from the health care providers about the anti-hormonal therapy and how to handle its side effects. They also lacked information about available rehabilitation programmes. The fact that those women who had attended rehabilitation experienced it positively and managed it well can motivate those providing medical care to develop better rehabilitation programmes for women diagnosed with breast cancer and receiving anti-hormonal therapy. Improved information about the anti-hormonal 
therapy and its side effects, together with rehabilitation programmes adapted to the individual's needs may make it easier for women to complete the treatment.

\section{ACKNOWLEDGEMENT}

The study was financed by the Breast Cancer Foundation in Sweden and Brunetti-Jacovone Foundation.

\section{REFERENCES}

Bandura, A. (1986). Social foundations of thought and action: A social cognitive theory. Englewood Cliffs, N.J: Prentice-Hall.

Buijs, C., de Vries, EG., Mourits, MJ., \& Willemse, PH. (2008). The influence of endocrine treatments for breast cancer on health-related quality of life. Cancer treatment reviews, 34(7), 640-655.

Burstein, HJ., Prestrud, AA., Seidenfeld, J., Anderson, H., Buchholz, TA., Davidson, NE., et al. (2010). American Society of Clinical Oncology clinical practice guideline: update on adjuvant endocrine therapy for women with hormone receptor-positive breast cancer. Journal of clinical oncology, 28(23), 3784-3796.

Burstein, HJ. (2007). Aromatase inhibitor-associated arthralgia syndrome. Breast, 16(3), 223-23.

Chrzanowska, J. (2002). Interviewing Groups and individuals in Qualitative Market research. Thousand Oaks: Sage.

Coleman, RE., Bolten, WW., Lansdown, M., Dale, S., Jackisch, C., Merkel, D., et al. (2008). Aromatase inhibitorinduced arthralgia: clinical experience and treatment recommendations. Cancer treatment reviews, 34(3), 275-282.

Davies, C., Godwin, J., Gray, R., Clarke, M., Cutter, D., Darby, S., et al. (2011). Relevance of breast cancer hormone receptors and other factors to the efficacy of adjuvant tamoxifen: patient-level meta-analysis of randomised trials. Lancet, 378(9793), 771-784.

Din, OS., Dodwell, D., Wakefield, RJ., \& Coleman, RE. (2010). Aromatase inhibitor-induced arthralgia in early breast cancer: what do we know and how can we find out more? Breast cancer research and treatment, $120(3), 525-538$.

Egan, MY., McEwen, S., Sikora, L., Chasen, M., Fitch, M., \& Eldred, S. (2013). Rehabilitation following cancer treatment. Disability and rehabilitation, 35(26), 2245-2258.

Fenlon D, Corner JL, Haviland, J.(2009) Menopausal hot flushes after breast cancer European Journal of Cancer Care $18: 140$ - 148 .

Fenlon D and Rogers A. (2007) The experience of hot flushes after breast cancer. Cancer Nursing 30:4 E1926.

Fenlon, D. Addington-Hall, J.M. O'Callaghan, A. Clough, J. Nicholls, P. and Simmonds, P. (2013) A survey of joint and muscle aches, pain and stiffness comparing women with and without breast cancer. Journal of Pain and Symptom Management. 46(4): 523-535.

Gaillard, S., \& Stearns, V. (2011). Aromatase inhibitor-associated bone and musculoskeletal effects: new evidence defining etiology and strategies for management. Breast cancer research : BCR, 13(2), 205.

Henry, NL., Giles, JT., \& Stearns, V. (2008). Aromatase inhibitor-associated musculoskeletal symptoms: etiology and strategies for management. Oncology, 22(12), 1401-1408.

Huang, X., Zhang, Q., Kang, X., Song, Y., \& Zhao, W. (2010). Factors associated with cancer-related fatigue in breast cancer patients undergoing endocrine therapy in an urban setting: a cross-sectional study. BMC cancer, 10, 453. 
Johnsson, A., Fornander, T., Olsson, M., Nystedt, M., Johansson, H., \& Rutqvist, L.E. (2007). Factors associated with return to work after breast cancer treatment. Acta Oncologica, 46(1), 90-96.

Kamberelis, G,. Dimitriadis. G. (2005). Focus groups. Strategic articulations of pedagogy, politics and inquiry, I Denzin, N., Lincoln,. Y. (ed.). Sage handbook of qualitative research. Sage, Thousand Oaks, CA.

Krueger, R.A (1994). Focus group interveiws: A practical guide for applied research. Sage, Thousand Oaks, CA.

Lazarus, R., \& Folkman, S. (1984). Stress appraisal and coping. New York: Springer-Verlag.

Li, CI., Daling, JR., \& Malone, KE. (2003). Incidence of invasive breast cancer by hormone receptor status from 1992 to 1998. Journal of clinical oncology, 21(1), 28-34.

Loibl, S., Lintermans, A., Dieudonne, AS., \& Neven, P. (2011). Management of menopausal symptoms in breast cancer patients. Maturitas, 68(2), 148-154.

Lundman, B., \& Graneheim, U. (2010). Kvalitativ innehållsanalys. Lund: Studentlitteratur.

Patton, M.Q. (2002). Qualitative research and evaluation methods. Thousand Oaks, CA.

Phillips, SM., \& McAuley, E. (2013). Social cognitive influences on physical activity participation in longterm breast cancer survivors. Psycho-oncology, 22(4), 783-791.

Rogers, L. Q., Shah, P., Dunnington, G., Greive, A., Shanmugham, A., Dawson, B., et al. (2005). Social cognitive theory and physical activity during breast cancer treatment. Oncology nursing forum, 32(4), 807-815.

Shapiro, SL., Lopez, AM., Schwartz, GE., Bootzin, R., Figueredo, AJ., Braden, C J., et al. (2001). Quality of life and breast cancer: relationship to psychosocial variables. J Clin Psychol, 57(4), 501-519.

Singer, O., Cigler, T., Moore, AB., Levine, AB., Hentel, K., Belfi, L., et al. (2012). Defining the aromatase inhibitor musculoskeletal syndrome: a prospective stud. Arthritis care \& research, 64(12), 1910-1918.

Stjarnfeldt J, Von Wachenfeldt A, Lidbrink E, Bordas P, Ahman J, et al. (2015) Breast Cancer Patients' Experiences and Reflections Regarding Information about Adjuvant Endocrine Therapy and its Side-Effects - A Focus Group Study. SOJ Nur Health Care 1In press

Skördåker, A, von Wachenfeldt, A, Lidbrink, E, Stjärnfeldt,J , Johnsson, A (2015). Short-And Long-Term Effects of Breast Cancer Diagnosis and Adjuvant Endocrine Treatment on Life Satisfaction. American Research Journal of Nursing 1(1) 13-21.

Stewart, BW., \& Wild, CP. (2014). World Cancer Report 2014. Lyon: WHO, International Agency for Research.

Wigertz, A., Ahlgren, J., Holmqvist, M., Fornander, T., Adolfsson, J., Lindman, H., et al. (2012). Adherence and discontinuation of adjuvant anti-hormonal therapy in breast cancer patients: a population-based study. Breast cancer research and treatment, 133(1), 367-373.

Ziller, V., Kalder, M., Albert, US., Holzhauer, W., Ziller, M., Wagner, U., et al. (2009). Adherence to adjuvant endocrine therapy in postmenopausal women with breast cancer. Annals of oncology, 20(3), 431-436.

Citation: Aina Johnsson, Professional Socialization in Nursing; Bodily Changes And Coping Strategies Due To Adjuvant Anti- Hormonal Breast Cancer Therapy-A Focus Group Study. ARJN Volume 2016; pp:1-9

Copyright (C) 2016 Aina Johnsson. This is an open access article distributed under the Creative Commons Attribution License, which permits unrestricted use, distribution, and reproduction in any medium, provided the original work is properly cited. 